\title{
Biphasic effect of arsenic on cell growth and its clinical significance
}

\author{
Dianjun Sun ${ }^{1,2}$ and Kewei Wang ${ }^{1,2,3,4,5 *}$ \\ ${ }^{1}$ Center for Endemic Disease Control, Chinese Center for Disease Control and Prevention, Harbin 150081, China \\ ${ }^{2}$ Key Laboratory of Etiology and Epidemiology, National Health and Family Planning Commission of the People's Republic of China, Harbin 150081, China \\ ${ }^{3}$ Institute of Cell Biotechnology, Harbin Medical University, Harbin 150081, China \\ ${ }^{4}$ Departments of Surgery, University of Illinois College of Medicine, One Illini Drive, Peoria, IL 61605, USA \\ ${ }^{5}$ Institute of Laboratory Animal Sciences, Chinese Academy of Medical Sciences \& Peking Union Medical College, 5 Panjiayuan Nanli, Beijing 100021, China
}

\begin{abstract}
Arsenic stimulates proliferation at low levels and inhibits cell growth at high concentrations, showing a biphasic effect on biological process. The biphasic effect requires that arsenic concentration must be maintained at an appropriate threshold to inhibit cancer cells during chemotherapy. The apoptosis may be a primary mechanism related to dual properties of the arsenic.
\end{abstract}

\section{Highlights}

»Arsenic is a carcinogen that can stimulate cell proliferation at low levels.

»Also, the arsenic is a cancer suppressor that inhibits cell growth at high concentrations.

» The biological role of arsenic shows a biphasic effect on cell growth.

»Apoptosis may be potential mechanism related to dual properties of the arsenic.

\section{Commentary}

Arsenic element (As) is widely distributed in nature, which is often combined with oxygen or sulfur to form compounds. The arsenic is closely associated with the biological process as well. Its pathophysiological characteristics are incorporated into the following aspects: (a) lowdose arsenic stimulates cell proliferation and carcinogenesis. When sodium arsenite was utilized to treat human HepG2 cancer cells or non-tumor HHI-5 hepatocytes, we found that the percentage of cell death was negative in initial phase, which means that the low-dose arsenite promotes cell growth (Figure 1). The arsenic could enhance cell viability at a narrow range of low concentrations. As the level of arsenite was increased to reach a critical point, it began to inhibit the proliferation and to accelerate cell death. The consistent result has been also reported by other study [1]. In different geological regions, the arsenic concentration in drinking water exceeds the standard content $(0.01 \mathrm{mg} / \mathrm{L})$ recommended by World Health Organization. Local residents who drink the arsenic-enriched water suffer from endemic arsenism [2]. The cancer incidences of various organs (e.g., skin, lung, kidney, urine bladder, liver and so on) in the endemic areas are significantly higher than those in non-endemic regions [3]. The arsenic had been identified as a human carcinogen by International Agency for Research on Cancer; (b) high concentration of the arsenic inhibits cell growth. In clinical practice, arsenic compounds (i.e. $\mathrm{As}_{2} \mathrm{O}_{3}, \mathrm{As}_{2} \mathrm{~S}_{2}$, etc.)

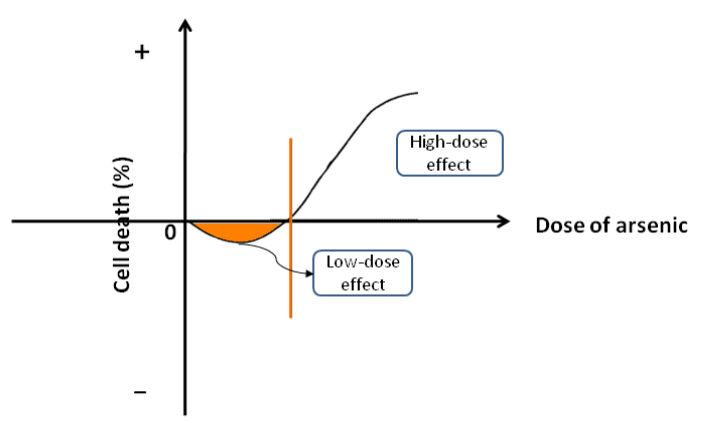

Figure 1. Schematic diagram of biphasic effect. The arsenic stimulates cell proliferation at low doses, whereas it accelerates cell death at high concentrations

are commonly used to kill cancer cells during chemotherapy. Moreover, the arsenide has been the first-line medicine for the treatment of some cancers such as leukemia and solid visceral neoplasm [4]. Sometimes, the arsenic compounds are used in combination with other drugs in order to obtain the best therapeutic effect. The arsenide not only induces tumor development, but also kills cancer cells as basic drug in clinical treatment. The arsenic has dual properties of carcinogen and cancer suppressor. Thus, a novel concept "biphasic effect" is proposed to describe its bidirectional role in cell growth.

What is exact mechanism that gives rise to dual properties of the arsenic? Currently, there is no clear answer for the question. However,

*Correspondence to: Kewei Wang, 157 Baojian Road, Nangang District, Harbin, China 150081, Tel: 0451-8750-3580, E-mail: kkww02052015@hotmail.com

Key words: arsenic, biphasic effect, endemic arsenism, carcinogenesis, chemotherapy

Received: April 10, 2019; Accepted: May 14, 2019; Published: May 17, 2019 
available data support that apoptosis plays a crucial role. The apoptosis is a gene-controlled, energy-consumed, suicidal process to maintain the tissue structure. A balance between apoptotic and anti-apoptotic competencies not only determines cell viability, but directly affects tissue function as well. So far, the apoptosis has been thought of as primary mechanism to connect carcinogenesis and cancer suppression. Inhibitor of apoptosis proteins (IAPs) has a powerful function in regulating cell survival and controlling apoptosis cascade [5]. Furthermore, the expression of IAPs is modulated by multiple nuclear factors, such as NF-kappa B, FoxA2, C/EBP-beta and so on [5]. Relationship between arsenic and apoptosis is worthy of careful investigation. We need more evidences to demonstrate that (a) low-dose arsenic inhibits apoptosis and stimulates cell proliferation. It is well known that the carcinogenesis has to overcome the resistance of apoptosis; (b) highdose arsenic triggers apoptosis and kills cancer cells. The core strategy for cancer treatment is to induce apoptosis of cancer cells. A reasonable hypothesis is that the arsenic inhibits apoptosis at low concentrations, whereas promotes apoptosis at high concentrations. It is also speculated that IAPs and their regulatory network may be responsible for the dual properties of arsenide.

An exploration on biphasic effect of arsenic (arsenide) has special significance in clinical treatment of the cancer. When arsenic compound is administered with other medicines together, dosage of the arsenic compounds is often reduced. Owing to dual properties of arsenic, we should evaluate the medicinal value of the arsenic compound while taking drugs in combination. At this moment, the local concentration of arsenide must be maintained at a specific level to induce the apoptosis of cancer cells. Otherwise, the arsenide may promote the proliferation of cancer cells. There is no any therapeutic effect, even an opposite outcome. Hence, we have to consider bidirectional response of the arsenide, especially in combination with other drugs. What is the exact threshold for arsenide to inhibit the tumor? How to administer the arsenide to reach the threshold concentration and keep it constant? What are biomarkers reasonable for monitoring the concentration of arsenide in the blood? Up to now there have been no answers for above questions. Biological characteristics of the arsenic also raise a new topic for the toxicology. In the traditional definition of toxicology, killing cells or increasing death rate is generally thought of as toxicological behavior. However, boosting the proliferation of cancer cells is also toxic to the body. So the behavior of low-dose arsenic is another aspect of toxicology. Perhaps it can be defined as inverse toxicology or reverse toxicology. Presently, we work on molecular markers that can estimate the concentration of arsenide in the blood and evaluate its therapeutic effect. Leukemia and solid tumors may require different concentrations of arsenic drugs (4). Clinical trials in large samples are needed to test the true role of arsenide in the treatment of various cancers. Moreover, the quantification of functional state of cells is the current focus.

In summary, the arsenic has biphasic effect on cell growth, which is manifested by the proliferation at low levels and inhibition at high concentrations. Because of the biphasic effect, a threshold of arsenic concentration must be maintained to kill cancer cells during cancer treatment. Otherwise, the arsenide may stimulate the proliferation of cancer cells, achieving a reverse effect. Preliminary studies reveal that the anti-apoptotic IAPs family and its regulatory network play an important role in arsenic biology. The apoptosis may be an essential mechanism related to dual properties of the arsenic.

\section{Declaration of interests}

The authors have nothing to disclose.

\section{Acknowledgments}

This work was supported by "The National Natural Science Foundation of China”, project number 81773367 . We thank professor Yang Jianbo's suggestion and advice in the preparation of manuscript.

\section{References}

1. Yedjou C, Tchounwou P, Jenkins J, McMurray R (2010) Basic mechanisms of arsenic trioxide (ATO)-induced apoptosis in human leukemia (HL-60) cells. J Hematol Oncol 3: 28 .

2. Tseng CH, Chong CK, Tseng CP, Centeno JA (2007) Blackfoot disease in Taiwan: its link with inorganic arsenic exposure from drinking water. Ambio. 36: 82-84.

3. Smith AH, Marshall G, Roh T, Ferreccio C, Liaw J, et al. (2018) Lung, bladder, and kidney cancer mortality 40 years after arsenic exposure reduction. Journal of the National Cancer Institute 110: 241-249.

4. Gill H, Yim R, Lee HKK, Mak V, Lin SY, et al. (2018) Long-term outcome of relapsed acute promyelocytic leukemia treated with oral arsenic trioxide-based reinduction and maintenance regimens: A 15-year prospective study. Cancer 124: 2316-2326.

5. Varfolomeev E, Blankenship JW, Wayson SM, Fedorova AV, Kayagaki N, et al. (2007) IAP antagonists induce autoubiquitination of c-IAPs, NF-kappaB activation, and TNFalpha-dependent apoptosis. Cell 131: 669-681.

Copyright: (C2019 Sun D. This is an open-access article distributed under the terms of the Creative Commons Attribution License, which permits unrestricted use, distribution, and reproduction in any medium, provided the original author and source are credited. 